\title{
Prevalent opportunistic infections associated with HIV-positive children 0-5 years in Benin city, Nigeria
}

\author{
Imade, P. E. ${ }^{1}$ and Eghafona, N. O. ${ }^{2 \star}$ \\ ${ }^{1}$ Department of Medical Microbiology, University of Benin Teaching Hospital, Benin City, Nigeria \\ ${ }^{2}$ Department of Microbiology, Faculty of Life Sciences, University of Benin, Benin City, Nigeria \\ E-mail:profeghafona@uniben.edu.ng
}

Received 10 June 2008; received in revised form 2 July 2008; accepted 4 July 2008

\begin{abstract}
A total of 620 HIV positive children 0-5 years attending University of Benin Teaching Hospital, Benin City, were examined in this study. They were grouped into less than 1 year and 1-5 years based on CDC classification system. 218 children were under 1 year and 402 were 1-5 years. The overall results showed that malaria infection recorded the highest prevalence with $71.10 \%$ in less than 1 year and $76.37 \%$ in $1-5$ years. This was followed by Oral Candidiasis $38.07 \%$ in less than 1 year and $50 \%$ in $1-5$ years. Bacteraemia had $23.40 \%$ and $30.60 \%$ in less than 1 year and $1-5$ years respectively. Diarrhoea, $14.22 \%$ in less than 1 year and $17.66 \%$ in $1-5$ years. Otitis media had $10.55 \%$ and $10.95 \%$ in less than 1 year and 1-5 years respectively. Similarly, 590 apparently healthy HIV-negative children within the same age group were evaluated for the presence of these infections. There was a statistical significance between opportunistic infections and HIV infection $(P<0.001)$. Malaria infection was the most prevalent opportunistic infection in this population and may probably be due to environmental condition of this locality as well as the low immune status of the children.
\end{abstract}

Keywords: Classification System, Malaria, Oral Candidiasis, Bacteraemia, Diarrhoea, Otitis Media

\section{INTRODUCTION}

Human Immunodeficiency Virus (HIV) infection is rapidly becoming a problem among children worldwide. An estimated 2.3 million children were living with HIV/AIDS at the end of 2006, 2 million of them in Sub-Saharan Africa. Most of these children acquire HIV from their HIV-infected mothers during pregnancy birth or breastfeeding (WHO, 2007). HIV infection in children causes a broad spectrum of disease with leads to profound immunosuppression. A hallmark of this process is the depletion of $\mathrm{CD} 4^{+}$ lymphocytes; which predisposes the patient to develop a variety of opportunistic infections. The frequency of opportunistic infections in HIV-infected children in the absence of highly active antiretroviral therapy (HAART), vary with age, pathogen exposure and degree of immunosuppression (Chakraborty and Shingadia, 2007; Merchant and Quadir, 2002).

The depletion of T-lymphocytes which result from the proliferation of HIV causes the immune system to become severely compromised and the usually benign infectious agents become pathogenic. A number of protozoa, fungi, viruses and bacteria can be responsible for opportunistic infections in HIV-infected persons who have progressed to AIDS (Cheesbrough, 2000; Constantine et al., 2005). Without HAART, the most common opportunistic infections in children include serious bacterial infections namely pneumonia and bacteraemia. The pneumonia most often manifests between 3 to 6 months of age in infants with vertically-acquired infection. Candidiasis (topical, oral, esophageal and tracheobronchial) is the most common fungal infection in HIV-infected children (Chakraborty and Shingadia, 2007). Common mycobacterial infections include tuberculosis (Mycobacterium tuberculosis) and a typical extrapulmonary tuberculosis or disseminated infection caused by the Mycobacterium avium-intracellulare complex. Diarrhoea is a frequent problem caused by pathogens such as Salmonella and Shigella. Septicaemia is a usual complication (Constantine et al., 2005).

Opportunistic infections continue to cause morbidity and mortality in patients with HIV infection throughout the world, with more incidence in developing countries where access to care and treatment is limited (Benson et al., 2004). Hence this work is carried out to ascertain the prevalent opportunistic infections associated with HIVpositive children $0-5$ years as well as measuring immune status of such children using CD4 count in Benin City, Nigeria.

\section{MATERIALS AND METHODS}

\section{Study Population}

A total of 620 HIV positive children consisting of 329 males and 291 females attending University of Benin Teaching Hospital, Benin City, were used for this study. Verbal informed consent was obtained from parents or guardians of the children. The population evaluated in this work were treatment naïve HIV-positive children diagnosed by polymerase chain reaction (PCR) for children 0-18 months and serological methods for children 
above 18 months of age. A total of 590 apparently healthy HIV negative children consisting of 311 males and 279 females were also evaluated in this work and these served as control. 3 millilitre of blood was collected from each patient and introduced into ethylene diaminetetraacetic acid (EDTA) bottle and mixed properly. All the samples were held at room temperature and processed within 2 hours of collection.

\section{Determination of CD4 Count and Percentage}

The CD4 cell count and percentage of the HIV positive children were analyzed by flow cytometry (Partec Cyflow Counter) made in Germany. The results obtained were recorded appropriately and was then categorized based on CDC classification system. For children less than 1 year, CD4 count greater than 1,500 cells/ $\mu \mathrm{L}$ or CD4 percentage greater than $25 \%$ was categorized into group 1 (no immunosuppression). CD4 count of 750-1,499 cells/ $\mu \mathrm{L}$ or CD4 percentage of $15-24 \%$ was categorized into group 2 (moderate immunosuppression). CD4 count less than 750 cells/ $\mu \mathrm{L}$ and CD4 percentage less than 15\% was categorized as group 3 (severe immunosuppression). However, for children 1-5 years, CD4 count greater than 1,000 cells $/ \mu \mathrm{L}$ or CD4 percentage greater than $25 \%$ was categorized into group 1 (no immunosuppression). CD4 count of $500-999$ cells/ $\mu \mathrm{L}$ or CD4 percentage of $15-24 \%$ was categorized as group 2 (moderate immunosuppression). CD4 count less than 500 cells/ $\mu \mathrm{L}$ or CD4 percentage less than $15 \%$ was categorized as group 3 severe immunosuppression (CDC, 1994).

However, no CD4 count and percentage was performed on the HIV-negative children.

\section{Laboratory Diagnosis of Infections}

Infections were diagnosed in the laboratory by standard methods as follows:

(i) Malaria Parasitaemia: Thin and thick blood films were made for each patient and stained with Field's stain at appropriate concentrations. The slides were examined microscopically using X100 objective.

(ii) Diarrhoea: Stool culture was carried out for each patient and inoculated into selenite- $F$ broth, MacConkey agar and Desoxycholate citrate agar (DCA). They were incubated at $37^{\circ} \mathrm{C}$ for 24 hours. The isolates were further identified using biochemical and cultural characteristics (Cowan and Steel, 1985).

(iii) Otitis Media: Ear swab was collected from each patient and cultured into blood agar, MacConkey agar and Chocolate agar. Plates were incubated at $37^{\circ} \mathrm{C}$ for 24-48 hours. The isolates were identified by biochemical and cultural characteristics (Cowan and Steel, 1985).

(iv) Bacteraemia: Blood culture was carried out in each patient and inoculated into glucose broth and thioglycollate broth. The broths were incubated at 37 ${ }^{\circ} \mathrm{C}$ for 1-10 days. Sub-cultured was made into solid media when growth was observed in the broth. The isolates were identified by biochemical and culture characteristics (Cowan and Steel, 1985).

(v) Oral Candidiasis: This was first observed macroscopically on the tongue of the patient. Swab was then taken and examined microscopically for the presence of yeast cells.

\section{Data Analysis}

The statistical significance of difference between HIV positive children and HIV negative children was tested using Chi-square $\left(\mathrm{X}^{2}\right)$ test, to show their relationship with various infections.

\section{RESULTS}

A total of 620 treatment naïve HIV-positive children were examined in this study. $218(35.16 \%)$ were less than 1 year while 402 (64.84\%) were between 1 and 5 years. The overall result showed that malaria parasite infection had the highest occurrence in all the categories irrespective of age group. This was followed by oral candidiasis and bacteraemia (Table 1a). Similarly, a total of 590 apparently healthy HIV-negative children were also examined in this study. $205(34.75 \%)$ were less than 1 year while $385(65.25 \%)$ were between 1 and 5 years (Table 1b). The overall distribution of opportunistic infections with respect to the different immunologic categories showed that single infections were more prevalent than mixed infections in the HIV-positive population studied (Table 2).

\section{DISCUSSION}

It was observed in this study with HIV-positive children that malaria infection had the highest prevalence in all the categories with an overall percentage of $71.10 \%$ among children less than 1 year and $76.37 \%$ in children between 1 and 5 years. This could be attributed to the fact that malaria constitutes the most public health problems in tropical Africa such as Nigeria. Similarly, the centre for disease control (CDC, 2006) reported that in children, HIV infection increases rates of malaria fever, severe disease and coma, with parasite density higher in children with advanced immunosuppression. Onifade et al. (2007) reported that HIV positive children within the age group 09 years recorded the highest prevalence of malaria infection with $66.7 \%$ in a study conducted in Ondo State of Nigeria. Thus there is a close relationship between Onifade et al. and this present work as regards the prevalence of malaria infection. However, this was followed by oral candidiasis, with an overall percentage of $38.07 \%$ among children less than 1 year and $50 \%$ in children 1-5 years. Dull et al. (1991) reported that oral candidiasis is common during the acute stage of HIV infection and that it occurs most commonly with falling $\mathrm{CD}^{+}$T-cell count in middle and late stage of HIV disease. It was observed in this study that the prevalence of oral candidiasis increases as immunity of the subjects 
Mal. J. Microbiol. Vol 4(2) 2008, pp. 11- 14

decreases (Table 1a). This tends to agree with the report of Dull et al (1991).
Bacteraemia was the next with $23.40 \%$ among children less than 1 year and $30.60 \%$ in children $1-5$ years. 
Mal. J. Microbiol. Vol 4(2) 2008, pp. 11- 14

Table 1a: Opportunistic Infections in HIV-Positive Children 0-5 years

\begin{tabular}{|c|c|c|c|c|c|c|c|}
\hline \multirow{2}{*}{$\begin{array}{l}\text { Age Group } \\
\text { (years) }\end{array}$} & \multirow{2}{*}{\multicolumn{2}{|c|}{$\begin{array}{c}\text { No. (\%) Treatment Naïve HIV-Positive } \\
\text { Children }\end{array}$}} & \multicolumn{5}{|c|}{ Opportunistic Infections } \\
\hline & & & Diarrhoea & Oral Candidiasis & Otitis Media & M.P & Bacteraemia \\
\hline \multirow[t]{4}{*}{$<1$} & Category 1 & $142(65.14)$ & $12(8.45)$ & $45(31.69)$ & $8(5.63)$ & $96(67.61)$ & $22(15.49)$ \\
\hline & Category 2 & $63(28.90)$ & $14(22.22)$ & $31(49.21)$ & $12(19.05)$ & 48 (76.19) & 20 (31.75) \\
\hline & Category 3 & $13(5.96)$ & $5(38.46)$ & $7(53.85)$ & $3(23.08)$ & $11(84.62)$ & $9(69.23)$ \\
\hline & Total & $218(100.0)$ & $31(14.22)$ & $83(38.07)$ & $23(10.55)$ & $155(71.10)$ & $51(23.40)$ \\
\hline \multirow[t]{4}{*}{$1-5$} & Category 1 & $185(46.02)$ & $16(8.65)$ & $66(35.68)$ & $13(7.03)$ & $136(73.51)$ & $32(17.30)$ \\
\hline & Category 2 & $138(34.33)$ & $23(16.67)$ & 79 (57.25) & $16(11.59)$ & $110(79.71)$ & 40 (28.99) \\
\hline & Category 3 & 79 (19.65) & $32(40.51)$ & $56(70.89)$ & 15 (18.99) & $61(77.22)$ & $51(64.56)$ \\
\hline & Total & $402(100.0)$ & $71(17.66)$ & $201(50.00)$ & $44(10.95)$ & 307 (76.37) & $123(30.60)$ \\
\hline
\end{tabular}

Key: M.P = Malaria Parasite

Table 1b: Similar Infections in HIV-negative Children $0-5$ years

\begin{tabular}{ccccccc}
\hline \multirow{2}{*}{ Age Group (Years) } & No. of HIV Negative children & \multicolumn{4}{c}{ Infections (\%) } \\
\cline { 3 - 6 } & 205 & Diarrhoea & Oral candidiasis & Otitis media & M.P & Bacteraemia \\
\hline$<1$ & 385 & $4(1.46)$ & $5(2.44)$ & $2(0.98)$ & $22(10.73)$ & $2(0.98)$ \\
$1-5$ & $4(1.04)$ & $5(1.30)$ & $4(1.04)$ & $35(9.09)$ & $3(0.78)$ \\
\hline
\end{tabular}

Key: M.P = Malaria Parasite 
Table 2: Distribution of Opportunistic Infections with respect to the different Immunologic Categories

\begin{tabular}{ccccc}
\hline $\begin{array}{c}\text { Age Group } \\
\text { (years) }\end{array}$ & Immunologic Category & $\begin{array}{c}\text { No. (\%) with Single } \\
\text { Infection }\end{array}$ & $\begin{array}{c}\text { No. (\%) with Mixed } \\
\text { Infection }\end{array}$ & Total \\
\hline$<1$ & Category 1 & $101(71.13)$ & $41(28.87)$ & 142 \\
& Category 2 & $32(50.79)$ & $31(49.21)$ & 63 \\
& Category 3 & $3(23.08)$ & $10(76.92)$ & 13 \\
$1-5$ & Total & $136(62.39)$ & $82(37.61)$ & 218 \\
& Category 1 & $136(73.51)$ & $49(26.49)$ & 185 \\
& Category 2 & $73(52.90)$ & $65(47.10)$ & 138 \\
& Category 3 & $23(29.11)$ & $56(70.89)$ & 79 \\
\hline
\end{tabular}

It was observed in this work that the severe immunosuppressed categories had more incidence of bacteraemia than the moderate and immunocompetent group. This could be attributed to the depressed immunity of the subjects. Nchabeleng et al. (2000) reported $15.5 \%$ prevalence in HIV positive children in a study conducted in a rural Kwa-zulu Natal Hospital in South Africa. Diarrhoeal infection recorded 14.22\% among children less than 1 year and $17.66 \%$ in children between 1 and 5 years.

The lowest prevalence was otitis media with $10.55 \%$ in children less than 1 year and $10.95 \%$ in children $1-5$ years. The overall distribution of opportunistic infections showed that single infection was more than mixed infection. However, mixed infection was more in the severe immunosuppressed categories and this group recorded the highest percentage of opportunistic infections.

However, apparently healthy HIV-negative children within the same age group were also evaluated for the presence of these aforementioned infections (Table 1b). This was done to ascertain if there is a relationship between the said infections and HIV infection. Statistical analysis using Chi-square showed that there is a relationship between opportunistic infection and HIV infection $(P<0.001)$. The prevalence of opportunistic infections recorded in this study could be attributed to the fact that the study population was treatment naïve and their immune system must have been subjected to series of attacks by the presence of the virus as can be seen from their CD4 count results (Table 1a).

In conclusion, the study showed that malaria infection is more prevalent among treatment naïve HIVpositive children in Benin City.

\section{ACKNOWLEDGEMENT}

We acknowledge with thanks the support given by the Medical Staff and Students of the University of Benin Teaching Hospital, Benin City.

\section{REFERENCES}

Benson, C.A., Kaplan, J.E., Masor, H., Alice, P. and Holmes, K.K. (2004). Treatment opportunistic infections Among HIV infected Adults and Adolescents: Recommendations and Reports.
Morbidity and Mortality Weekly Report 53 (RR 15):1112.

CDC (1994). Revised classification system for HIV in children less than 13 years of age. MMWR 43:RR12.

CDC (2006). The link between malaria and HIV. Centres for Disease Control, Division of Parasitic Diseases, 13 January, 2006.

Chakraborty, R. and Shingada, D. (2007). Treating opportunistic infections in HIV-infected children (extended). Guidelines for the children's HIV Association (CHIVA)

Cheesbrough, M. (2000). Paediatric HIV disease. District Laboratory Practice in Tropical Countries. Cambridge University Press pp 256.

Constantine, N.T., Saville, R.D. and Dax, E.M. (2005). Retroviral testing and Quality Assurance. Essentials for Laboratory Diagnosis pp 56-58.

Cowan, S.T. and Steel, K.J. (1985). Manual for the identification of Medical Bacteria. $4^{\text {th }} \mathrm{Ed}$. London. Cambridge University Press.

Dull, J.S., Sen, P., Raffanti, S. et al. (1991). Oral candidiasis as a marker of acute retroviral illness. Southern Medical Jounal 84:744-735, 739.

Merchant, R.H. and Quadir, Z.A. (2002). Management of opportunistic infections in paediatric HIV. Indian Journal of Paediatric 69(12):973-977.

Nchabeleng, M., Yeung, S., Escott, S., Wilkinson, D. and Sturm, A.W. (2000). Bacteraemia in HIVinfected children in a rural Kwa-zulu Natal Hospital. Int. Conf. AIDS. July 9-14; 13: abstract No. MoPeB2202.

Onifade, A.K., Akanni, E.O. and Mewoyeka, O.O. (2007). Incidence of Malaria Infection among Human Immunodeficiency Virus patients in Ondo State, Nigeria. Middle-East Journal of Scientific Research 2(2):48-53.

WHO (2007). Paediatric HIV and treatment of children living with HIV. Report of the first meeting of the subcommittee of the Expert Committee on the selection and use of Essential Medicine on Children's Medicines. Geneva, $9^{\text {th }}-13^{\text {th }}$ July, 2007. 